\title{
Scaling-up Motivation of Southern NGOs A Case Study on Internationalization of YCAB Foundation
}

\author{
Fitri Rofiyarti ${ }^{1 \mathrm{a}}$; Vinsensio Dugis $^{2}$ \\ ${ }^{1}$ Department of Education, Universitas Narotama, Surabaya, Indonesia \\ ${ }^{2}$ Department of International Relations, Universitas Airlangga, Surabaya, Indonesia \\ ${ }^{a}$ Corresponding author: rofiyartifitri@yahoo.fr
}

\begin{abstract}
Activities of Non Governmental Organization (NGOs) around the world vary by degrees, as do their relationships with international organizations, corporations and other civil society organizations. Until recently, it is widely accepted that NGOs that able to operate internationally mostly coming from developed countries, while due to various limitations the ones from developing countries tend to operate locally which in most cases working together with NGOs from developed countries. Scaling-up is a term referring to a means by which smaller NGOs especially from developing countries or Southern NGOs (SNGOs) can participate at the world table or operate internationally. Looking at the experience of Yayasan Cinta Anak Bangsa (YCAB Foundation) as an example of SNGOs that has successfully operated internationally, this paper reveals several motivations for the scaling-up of SNGOs. The paper identifies three related motivations, namely the agenda of south-south transfer, NGOs bargaining power, and a competitive environment faced by NGOs. While the first motivation is normative in lieu of YCAB Foundation as a non-profit organization, the other two motivations tend to be pragmatic and closely related to economic considerations.
\end{abstract}

Keywords-internationalization, motivation, NGOs, scaling-up, NGOs, YCAB Foundation

\section{INTRODUCTION}

Worldwide recognition about the important role played by NGOs on many global governance issues has at least been proven by two trends; the significant increasing numbers of NGOs officially registered at the United Nations in the last two decades and their worldwide operations ranging from developed to developing countries [1, 2]. While their activities around the world vary by degrees, NGOs can be chategorised according to their headquarters, and that is of Northern NGOs (NNGOs) for NGOs with their headquarters located in or originating from developed OECD countries and Southern NGOs (SNGOs) for NGOs located or originating from lowincome and middle income countries [3].

Most NGOs are undeniably formed in developed countries but operate in developing countries where development issues are much more complex compared to in the developed countries [4]. This geographic situation places SNGOs closer to the 'real' development issues that needed to be addressed and makes them often getting better responses than the NNGOs. Nevertheless, it cannot be denied that the greatest support, especially on funding, institutional aid, and information comes from the NNGOs [5].
In Indonesia, NGOs are known widely as Organisasi Non Pemerintah (ONP) emerged in the 1970s when Indonesia's development progressed rapidly [6]. However, as this development increased unevenly, it came along with various social issues ranging from poverty, low levels of education, repression of human rights to environmental degradation. These problems then gave birth to an increasingly mushrooming community organization in the 1990s including Yayasan Cinta Anak Bangsa (YCAB) as a local NonGovernmental Organization (NGO) formed in 1999.

The YCAB then grew rapidly where at one point it was able to be rank 74th out of the world's 100 best NGOs, and became the only Indonesian NGO that entered in the rankings. Apparently, this success cannot be separated from its decision to go international by transforming from YCAB to YCAB Foundation through the establishment of YCAB International Inc. in Atlanta, Georgia in 2007. Through concrete steps by expanding the scope of activities in Myanmar, Pakistan, Afghanistan, Mongolia and Uganda, the YCAB Foundation has grown rapidly and succeeded in becoming an NGO that received UN-ECOSOC Special Consultative Status.

FIGURE 1. THE YCAB FOUNDATION

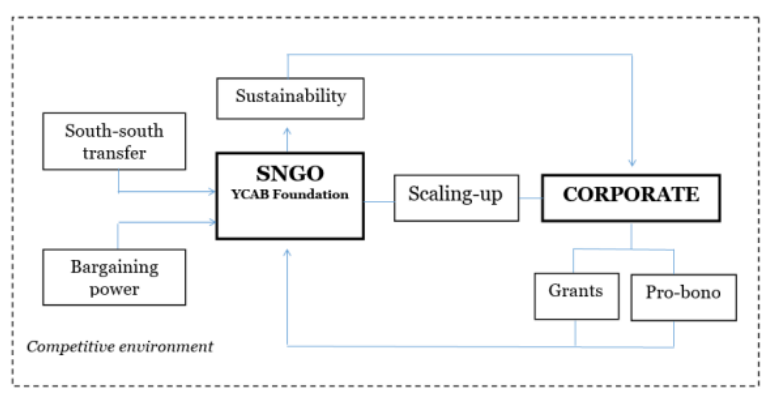

Since then, the YCAB Foundation has been able to contribute not only to the regional territory of Indonesia, but also to other least developed countries. In other words, it has been able to involving in transnational activities following its scaling-up transformation from the YCAB to the YCAB Foundation in 2007. This achievement then becomes interesting to be studied further, especially about the background and the process that happened behind the success of YCAB Foundation to expand its influence which can be said out of mainstream nature of SNGOs. As a Southern 
NGOs, what are the motivations behind the YCAB scaling-up transformation?

\section{RESEARCH METHOD}

Data collection during the research of this paper was taken through the combination of library study, face-to-face interviews, interviews by telephone, and communications via emails. Interviews were conducted with resource persons who were deemed able to answer the focus of the research. Email correspondences were exchanged with the founder of the YCAB Foundation, the Chief Operational Manager, and the Chief of Partnership of the YCAB Foundation. The overall results became primary data used in the paper, while secondary data were obtained from literatures in official reports from organizations, related books, mass media coverage, and other relevant sources.

The data were then anaysed using a scaling-up strategy as an approach. As an internationalization strategy, scaling-up comprised of three main tools namely expanasion, replication, and collaboration [7]. This analysis, with a qualitative method, was aimed at paricularly gaining insights into the motivations behind the scalling-up of the YCAB Foundaion.

\section{RESUlT AND DisCUSSION}

The scaling-up transformation of the YCBA began when in 2007 it expanded internationally by forming YCAB International Inc. headquartered in Atlanta, Georgia, USA. Equally, it also committed to programs implemented into the least developed countries such as in Myanmar, Pakistan and Afghanistan. To achieve this mission, the YCBA Foundation has also explored opportunities to collaborate with other partners who share a common goal to empower the young generation through a holistic development programs. In 2009, the YCAB Foundation has started to collaborate and building strategic alliance with the British Council, Grameen Foundation, and Conditional Cash Transfer with ILO. Beginning from 2007, the foundation officially registered as one among the UN-ECOSOC consultative groups.

When examined by digging further information from exposed in the media, in the case of YCAB Foundation as a representation of SNGOs, three factors can be identified as driving factors behind the scaling-up of YCAB, namely southsouth transfer agenda, increasing NGOs bargaining power, and growing competition among NGOs. The following chart illustrates the three factors influence the scaling-up transformation of the YCAB as a local SNGO to the YCAB Foundation as an international NGO operating with certain corporate value.

\section{A. South-South Transfer Agenda}

When it is linked to concerning issues in containing in the vision and mission of the organization, this transnational activity has been basically the YCAB Foundation's reaction to similar issues in different geographic areas, especially in least developing countries. The YCAB Foundation is driven by its idealism seeking to address issues related to its three main pillars (HeLP, HoLD, and HoPE) regardless of geographic boundaries, and this has been in line with the south-south transfer agenda which has two main goals: sharing best practice and testing the theory of change of the organization.

South-South Transfer (SST), which in some literature also referred to as South-South Collaboration (SSC) is one of the frameworks designed to speed up the development agenda in which developing countries no longer rely entirely on developed countries. Developing countries that have previously been considered one step ahead or have found a formula related to a particular problem replicate the program to apply to other developing countries that have similar problems. Thus, in the case of SNGOs for example, the relevant SNGO will replicate its program which is considered successful, either by expanding directly to the country and cooperating with NGOs in the destination country. This model is considered to be more effective in addressing a particular problem although often still have limitations on funding issues.

The expansion of the YCAB Foundation to other developing countries has also been based on the south-south transfer principle. This is revealed in a statement by the chief of YCAB Foundation, Colondam, stating that, "when the YCAB has had a wide coverage in Indonesia, we think to share our best practices and models to other developing countries, carry Indonesia's name, one of YCAB legacy for the world”. It is clear from the statement that the scaling-up is one effort to share best practice and test whether the successful program in Indonesia would bring the same impact when they are applied in other countries. The motivation based on the south-south transfer agenda is also clearly seen from the selected destination countries by the YCAB Foundation, which they are all developing countries such as Myanmar, Pakistan, Afghanistan, Uganda and Mongolia.

The programs run by YCAB Foundation outside Indonesia are not necessarily local programs that are applied in the destination country but are a form of adaptation. The program is tailored to the local needs of the destination areas, such as the Wonderful Garden program undertaken in Myanmar. One of the most well-run pillars of the YCAB Foundation in Indonesia is the HoLD (House of Learning and Development) program, the Wonderful Garden program focusing on literacy in underprivileged children in Myanmar has a common thread with HoLD programs. Similarly, the Digital Inclusion Class program, the program initiated with the aim of introducing computers and the Internet has also been successfully run in Indonesia. The existence of similarity characteristics on the problems faced in Indonesia and Myanmar made YCAB Foundation challenged to then test the program that has been successfully executed locally and even nationally in Indonesia as well as take part in the south-south transfer. It is this motivation that strengthens the YCAB Foundation for scalingup by selecting developing countries as destination countries. Through this south-south transfer framework, the YCAB Foundation has also proved that the strategy has been done at the local level. By scaling up, YCAB can get more lessons learned as validation that the premise YCAB takes in its 
approach to youth development is universal, it can be used in any country especially when the YCAB fungus changes from implementer to enabler.

In addition to the encouragement of the south-south transfer agenda, with respect to the achievement of the YCAB Foundation, which ranked 73th in the world's 100 best NGOs and is the only Indonesian NGO, the scaling-up is one of the points of assessment along with impact, sustainability and innovation. Colondam mentioned that trans-nationalization must be done when an NGO needs to validate its premise. "Not just sharing best practice, but inspiring as 'best fit' organization to address the needs in its operation geographic." At this point, the motivation that drives the internationalization of YCAB Foundation can be said to be principal, in accordance with the existence of the YCAB Foundation as a non-profit organization.

\section{B. NGOs Bargaining Power}

From an organizational point of view, in contrast to the normative first driving factor, further motivation can be said to be very pragmatic. Trans-nationalization proved to be an inevitable big push of the organization's interest to get funding. In other words, these second driving forces are closely related to economic motives. Existence at the international level will make it easier for YCAB Foundation to access grants from outside Indonesia. More specifically, scaling-up is also a strategy to work with corporations, considered to have large capacity to contribute financial support to NGOs.

With sufficient financial support, NGOs such as the YCAB Foundation could have a more bargaining power, especially with the presence of corporations that support it financially. The existence of corporations behind the success of an NGO cannot be easily denied even though these two actors can be said to be contradictory and vulnerable to conflict. In fact, in NGOs who have changed their organization from pure NGOs to social entreprise, releasing dependence on corporations as sponsors in their activities is not easy to do. It is also supported by the need of the company to run corporate social responsibility that becomes their obligation. This partnership is one way YCAB Foundation to be able to realize the program in accordance with its vision and mission, as well as the sustainability of the organization as a whole. In other words, YCAB Foundation makes transnational programs that they have done as one of the 'selling points' to the corporation to be partners. Furthermore, this cooperation will facilitate YCAB Foundation in forming networking.

In addition to increasing the bargaining power that is owned, scaling-up also help a lot in the financial side of the organization. The YCAB Foundation's Chief of Partnership says that by having an international program, the opportunity to get grants from outside will also get bigger. Thus, the existing motivation is not just related to the program, but more pragmatic is the desire to access a larger aid, which is not available in the country. The motivation for the expansion of YCAB Foundation into the United States for the first time before executing international programs into least developed countries was driven by the desire to have an online donation platform. This desire is constrained because it has no status as a US-based entity. Colondam explained that at that time it was difficult to take care of online donations because Paypal would not cooperate with all organizations outside the United States. For this reason a legal entity in the United States, Colondam feels this to be one of discrimination especially for NGOs in developing countries.

The positive implications of the good relationship between the YCAB Foundation and the corporation are not only in the form of grants, but also pro bono services. It is this pro bono service that can be said to give significant influence to the progress of the YCAB Foundation. Evidently, some big companies provide pro-bono assistance at YCAB Foundation such as Accenture, BCG (Boston Consulting Group), EY (Ernst \& Young), Palladium, and Norton Rose Fullbright. These companies contribute greatly to the YCAB Foundation for free, from the creation of the YCAB Foundation strategy to the broadest, the use of IT in the organization, including in tax management. Other partners are Achilles, ANZ, Bank Indonesia, Chevron, CIMB Niaga, Corsa, Citibank, Ford, HSBC, Levi's, Microsoft, PUMA Energy, Telkomsel, Tower Bersama Group, Unilever, Samsung, Johnson, and Standard Chartered.

\section{Growing Competition}

The transnationalization undertaken by SNGOs is further fueled by the growing competition among NGOs. It is part of a survival strategy in an increasingly competitive NGOs environment. Internationalization could make SNGOs 'winning' the existing competition because corporations often see their track record before corporations decide which NGOs they support financially. The rapidly changing environment is having major implications for the role of NGOs, their sources of funding, the nature of their relationships and their activities. When the number of NGOs operating in a specific geographic area increases, increasing competition for funding and contact with target groups becomes evident. The large number of NGOs and high competition in the non-profit sector makes donors have many options to projects they can choose to fund. The company will look for NGOs who have good governance because of corporate branding as one of the main goals of the company to collaborate that will be at stake. Consequently, NGOs must have the ability to 'sell' their organizations by expanding not only their agendas but also capabilities and assets.

This growing competitive situation is acknowledged by the Chief Manager of Partnership of the YCAB Foundation, Firza Imam Putra, where in an interview saying that the existence of competition among NGOs is actually also bring a positive impact, this can make NGOs improve the quality standards and transparency of the organization. This competitive environment is important as a driving factor, either directly or indirectly to enhance the organizational capabilities of NGOs, especially in formulating strategies in dealing with its 
competitors. With the increasing quality of NGOs, their expected impacts on society also increase. Thus competition among NGOs can be fierce, for both donors and for media exposure that leads to status and funds, and can choke off trust between NGOs, making cooperation and coordination impossible.

\section{CONCLUSION}

The motivation for scaling-up of SNGOs has similarities with NNGOs. When looking at the nature of the two especially if it is associated with geographical and economic elements, NNGOs are normatively based more on principal motivation whereas SNGOs are controlled by pragmatic motivation. However, in reality both are based on normative motivation (related to issues and principal values), which in turn are more dominated by pragmatic motivation (related to survival in a competitive environment). Driving forces are interconnected with each other and form a cycle with changes in the characteristics of the motivation. Initially, the motivation is principal based on the voluntarism and idealism of the NGOs. Nevertheless, at some point when the NGOs' environment became more competitive, this motivation shifted to pragmatic with the aim of survival.

\section{ACKNOWLEDGMENT}

This paper is a reworking version from a Master thesis by the first author who was supervised by the second author in the Department of International Relations, Universitas Airlangga Surabaya. Both authors thank to those who have in various ways helped the process of the research for that Master thesis.

\section{REFERENCES}

[1] F. Dar, "Emerging roles of NGOs in the world's socio-political affairs", International Journal of Peace and Development Studies, Vol. 6 no. 1, 2015, pp. 1-9.

[2] D. Lewis, "Nongovernmental Organizations, definition and history", Helmut K. Anheier, Stefan Toepler, Regina List (eds.), International Encyclopedia of Civil Society, Springer, pp. 1-6.

[3] A. Fowler, "Building partnerships between Northern and Southern development NGOs: issues for the 1990s”, Development in Practice, Vol. 1, no. 1, 1991, pp. 5-8.

[4] N. Kanji and D. Lewis, Non-Governmental Organizations and Development, Routledge, 2009.

[5] A. Fowler and R. James, "The role of Southern NGOs in development cooperation”, Oxford, INTRAC, 1994.

[6] M.T. Ford, "NGO as outside intellectual: A history of non-governmental organisations' role in the Indonesian labour movement", $\mathrm{PhD}$ thesis, School of History and Politics, University of Wollongong, 2003. http://ro.uow.edu.au/theses/ 150.

[7] P. Uvin and D. Miller, "Paths to scaling-up: alternative strategies for local Nongovernmental Organizations”, Human Organization: Fall 1996, Vol. 55, no. 3, Fall 1996, pp. 344-354. 